Cite as:

Rios, L., Pereira, C., Correia, A., and Parente, M. (2016). Small Strain

Stiffness of Sand under Different Isotropic and Anisotropic Stress Paths

Measured by Seismic Wave-Based Testing Techniques. Geo-China 2016: pp.

224-231.

\title{
Small Strain Stiffness of Sand under Different Isotropic and Anisotropic Stress Paths Measured by Seismic Wave-Based Testing Techniques
}

\author{
Luís Rios ${ }^{1}$, Cláudio Pereira ${ }^{2}$, António Gomes Correia ${ }^{3}$, Manuel Parente ${ }^{4}$
}

\footnotetext{
1 MSc Researcher, Civil Engineering Department, University of Minho, Departamento de Engenharia Civil, Universidade do Minho, Campus de Azurém, 4800-058 Guimarães, Portugal. Email: luisriosrios@hotmail.com

${ }^{2} \mathrm{PhD}$ Researcher, Civil Engineering Department, University of Minho, Campus de Azurém, 4800058 Guimarães, Portugal. E-mail: cpereira@civil.uminho.pt

${ }^{3}$ Full Professor, ISISE, School of Engineering, University of Minho, Campus de Azurém, 4800-058 Guimarães, Portugal. E-mail: agc@civil.uminho.pt

${ }^{4} \mathrm{PhD}$ Researcher, Civil Engineering Department, University of Minho, Campus de Azurém, 4800058 Guimarães, Portugal. E-mail: map@civil.uminho.pt
}

\begin{abstract}
This paper presents a study of a uniform dry sand compacted by the pluviation method and submitted to different isotropic and anisotropic stress paths. The stress states were performed in two distinct triaxial cells using specimens of $100 \mathrm{~mm}$ and $150 \mathrm{~mm}$ diameter in order to assess also the scale-effects. The small strain stiffness for each stress state was evaluated in both triaxial cells by bender elements which were assembled vertically and horizontally for the comparison of the shear wave velocity in the two directions. In the specimens of $100 \mathrm{~mm}$, additionally to the bender elements in the vertical direction, accelerometers were used for the improvement of the results accuracy. All tests results were analysed in order to assess the initial fabric (inherent) anisotropy and the induced anisotropy by the different anisotropic stress paths.
\end{abstract}

\section{INTRODUCTION}

The anisotropy of ground materials can have an important impact on geotechnical design. This property is not only particularly important in clays, due to the highly anisotropy of the material which can reach values $(\mathrm{Gh} / \mathrm{Gv})$ of around 2(Leung \& $\mathrm{Ng}$ 2004), but it also has a relevant impact on sands, as addressed by literature (Kuwano et al. 1999) . These authors state that the anisotropy of a material is affected by its geological characteristics, compaction method and stress conditions. 
The present study is based on the use of bender elements, which allow the assessment of shear modulus in different directions. The tests presented in this paper aim to study inherent and stress-induced anisotropy of a monogranular sand through bender elements measurements in vertical and horizontal directions. To improve reliability of the results, namely in terms of scale effect and bender elements interpretation, tests on a triaxial chamber with different dimensions were also carried out, and two sets of bender elements (vertical) and accelerometers were used.

\section{MATERIALS AND METHODS}

Tests were performed in two distinct triaxial cells using specimens with $100 \mathrm{~mm}$ and $150 \mathrm{~mm}$ diameter. The cells were fitted with piezoceramic bender elements in the top cap and bottom pedestal, as well as horizontal bender elements and accelerometers for purposes of comparison and accuracy improvement of the results (Ferreira et al. 2013).

The $150 \mathrm{~mm}$ triaxial chamber includes bender elements in the top cap and bottom pedestal in order to measure the shear wave velocity $\mathrm{V}_{\mathrm{p}}$, a horizontally polarized wave propagating vertically. Additionally, a second pair of horizontal bender elements mounted on the side of the specimen was used to measure the velocity $\mathrm{V}_{\mathrm{h}}$, horizontally propagating waves polarized horizontally. Each bender element is $11 \mathrm{~mm}$ wide and $1.8 \mathrm{~mm}$ thick and penetrates approximately $2 \mathrm{~mm}$ into a specimen. The horizontal bender elements coupling were secure by means of a rubber membrane, ensuring a tight contact with the specimen and the maintenance of membrane integrity during the test.

On the other hand, the $100 \mathrm{~mm}$ triaxial cell uses a combined system equipped with a total of four sensors: two bender elements (from GDS Instruments) and two accelerometers (Martins \& Gomes Correia 2015). The transmitter bender element generates horizontally polarized waves vertically propagated through the specimen, which are received by the remaining transducers, the receiver bender elements and the two accelerometers. The accelerometers used are from Bruel \& Kjær (type 4513-001, $100 \mathrm{mV} / \mathrm{g}$ sensitivity, $\pm 50 \mathrm{~g}$ measuring range, $1 \mathrm{~Hz}$ to 10 $\mathrm{kHz}$ frequency range, $12.7 \mathrm{~mm}$ in diameter, $15.65 \mathrm{~mm}$ in height, $9.0 \mathrm{~g}$ in weight). Its attachment to the specimen is possible by means of threaded head pivots. Accelerometer 1 is placed $30 \mathrm{~mm}$ from the specimen base and accelerometer 2100 $\mathrm{mm}$ from AC1(Ferreira et al. 2013; Martins 2011).The electronic equipment used to perform the BE measurements on both setups involved a TTi Huntingdon TG2511 function generator capable to generate several wave shapes (sinusoidal,) and configurations (continuous) as well as a digital oscilloscope 4424 from Pico Technology, with 4 channels - $1 / 2$ channels - $80 \mathrm{Ms} / \mathrm{s}$ and 3/4 channels - $20 \mathrm{Ms} / \mathrm{s}$ of sampling rate, with 12 bits of resolution (up to 16 bits with resolution improvement). The measurements were performed on the time domain.

The chosen material was a monogranular sand with a maximum void ratio and minimum void ratio of 0.882 and 0.655 respectively and $2.63 \mathrm{~g} / \mathrm{cm}^{3}$ of soil particle density. Specimens were assembled by the pluviation method.In order to assess the inherent and stress-induced anisotropy, a specimen was tested on 3 different 
stages. Firstly, the specimen was submitted to different levels of isotropic stress conditions, with horizontal and vertical bender elements measurements, for the assessment of the inherent/fabric anisotropy of the sand (stage 1). Secondly, the specimen was submitted to an anisotropic stress state with an effective stress ratio $(\mathrm{K}=\mathrm{sh} / \mathrm{sv})$ of 0.5 , Bender element measurements were performed in order to evaluate the anisotropy of the sand under anisotropic stress conditions (stage 2). Lastly, the specimen was once again tested under isotropic conditions for the evaluation of the stress-induced anisotropy of the sand (stage 3). The anisotropic and isotropic paths can be seen in Fig. 1.

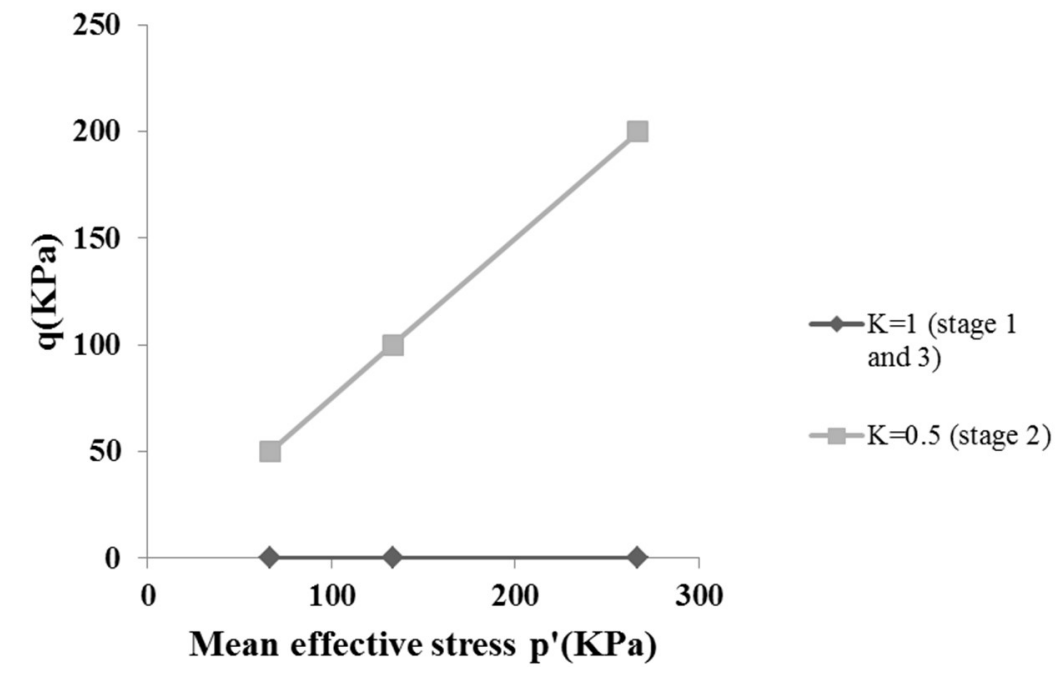

Fig. 1 Stress path of the first specimen

Another specimen was assembled in the $150 \mathrm{~mm}$ triaxial chamber through the pluviation method for the evaluation of the stress-induced anisotropy. The test sequence can be observed in Fig. 2. The methodology followed in this case was:

- The specimen was submitted to an anisotropic stress level with the bender elements measurements (points 1,4,7);

- Unloaded the deviatoric stress(q) for the assessment of the correspondent induced anisotropy (points 2,5,8) ;

- Return to the previous anisotropic stress level and increase the mean effective stress (anisotropically) to repeat the process (points 3,6).

Numbers represent the order by which the test was carried out. The main purpose of this experiment was to evaluate the stress-induced anisotropy at each stress state with cycles of loading and unloading. 




Fig. 2 Stress path of the second specimen

\section{RESULTS}

At isotropic stress conditions (stage1), the evolution of the shear modulus with the confining stress can be assessed by analysing Fig. 3, which illustrates that the horizontal shear moduli $(\mathrm{Gh})$ is significantly higher than the vertical shear moduli $(\mathrm{Gv})$. Since some level of confinement was applied to the material from initial stages, these results do not completely illustrate the fabric anisotropy of the material. However, the applied isotropic stress does not alter the material structure (i.e., there is no rearrangement of particles as a result of the applied confining stress), allowing for a comparison between the anisotropy in the early stages of the stress and the fabric anisotropy of the sand. As such, these results are intended to demonstrate the fabric anisotropy of this sand. The variation of the anisotropy with the mean stress is low, falling within a range of 1.25-1.27.

These results are similar to those obtained under isotropic stress conditions by Amat (2007) in the Hostun sand, as can be seen in Fig. 3, and by Kuwano et al. (1999) with the Toyura sand, observing a Gh/Gv of 1.2. These studies suggest the significant influence of particle size and shape, as well as the impact of the compaction method, in this case the pluviation method (also used in this work), on the fabric anisotropy of the material. According to Fioravante (2000), the higher values associated with the horizontal modulus when compared to the vertical modulus may be caused by the pluviation technique, which results in a slightly oriented structure. 


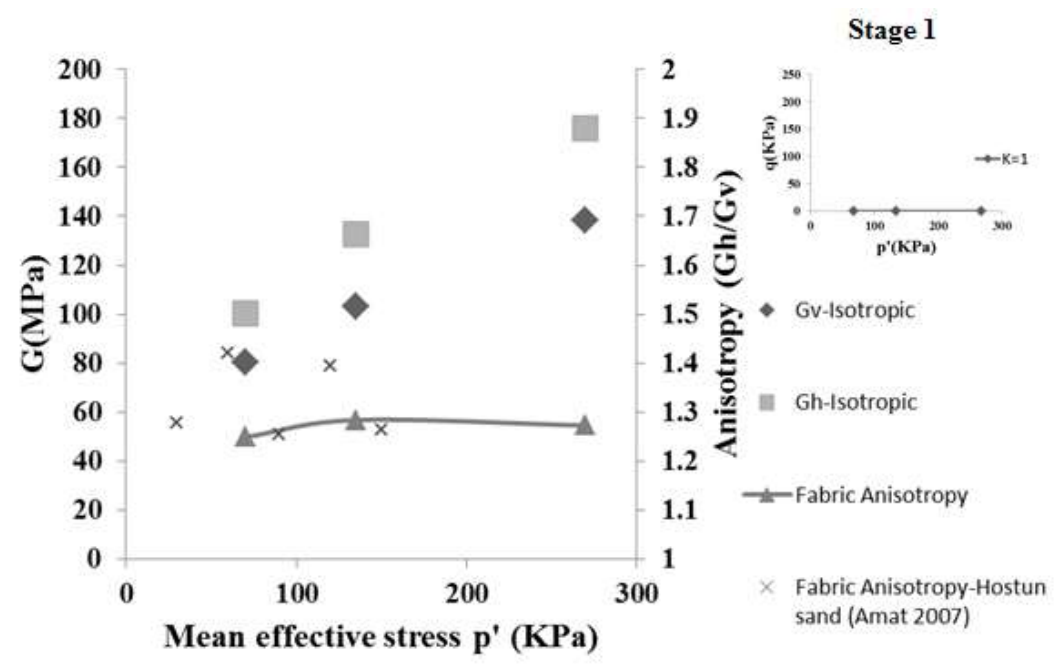

Fig. 3 Shear modulus of the sand under isotropic conditions and fabric anisotropy

The analysis of Fig. 4 shows the anisotropic stress conditions (stage 2) have a significant influence on the sand shear modulus. In fact, one can easily infer a reduction of the horizontal stiffness and an increase of the vertical stiffness for the same mean effective stress. Thus the anisotropy presented a stress-induced modification, in the range of 1.04-1.06, which are similar to the results obtained by Kuwano et al. (1999) with the Toyura sand $(\mathrm{Gh} / \mathrm{Gv}=1.02)$, although relatively higher than those obtained by Belloti et al. (1996) with the Tiscino sand (Fig. 4). However, this difference may be partially explained by the differences in the fabric anisotropy, which influences results.

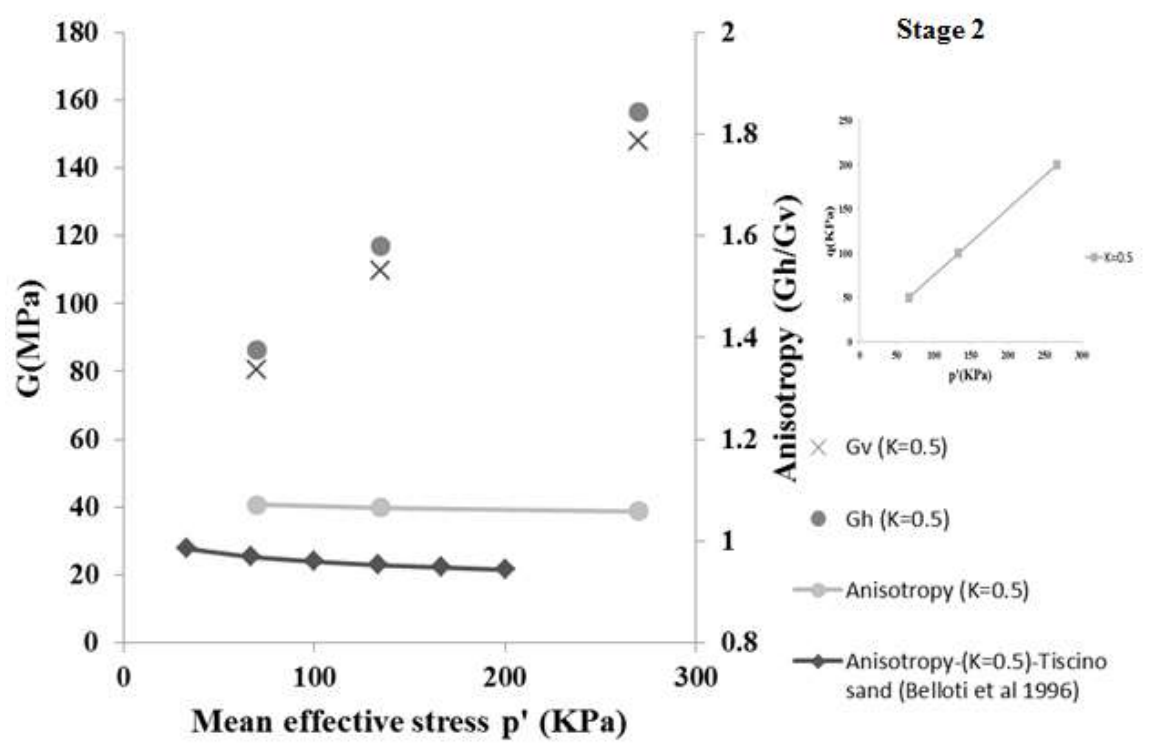

Fig. 4 Shear modulus of the sand under anisotropic conditions and induced anisotropy

Fig. 5 shows the modulus results associated with stage 3, as well as the anisotropy results for all stages. The anisotropy variation between the 3 stages is clearly evident. The anisotropy results in the final stage of the experiment fall between the 
fabric results (stage 1) and the anisotropic stress results (stage 2). Thus, the specimen under isotropic conditions (stage 3 ) recovers some of its initial properties when compared with stage 2 , but it does not reach the anisotropy levels of stage 1 , due to its stress history.

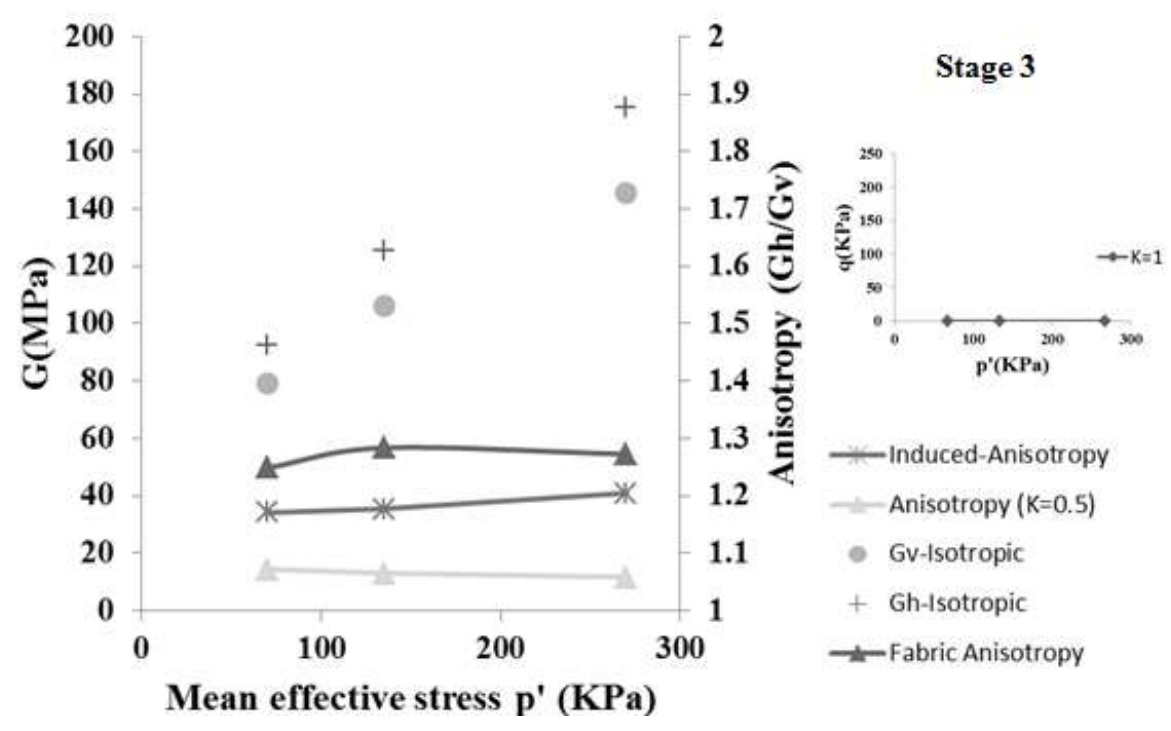

Fig. 5 Shear modulus of the sand under isotropic conditions and comparison of anisotropies

Since the modulus in a direction depends on the stress in that direction (Gomes Correia et al. 2001), the variance of the horizontal stress to vertical stress ratio obviously affects the anisotropy of the material. The $\mathrm{K}$ influence on the anisotropy was reported by several authors(Kuwano et al. 1999; Belloti et al. 1996; Fioravante 2000; Rampelo \& Viggiani 2001).

Fig. 6 shows the variation of the $\mathrm{Gh} / \mathrm{Gv}$ ratio with $\mathrm{K}$. The results obtained with this sand show a good agreement with results from other authors, particularly in terms of observed tendency. Even though this work did not consider tests with stress ratios above 1, it appears that these have a much smaller impact on the anisotropy than stress ratios below 1 .

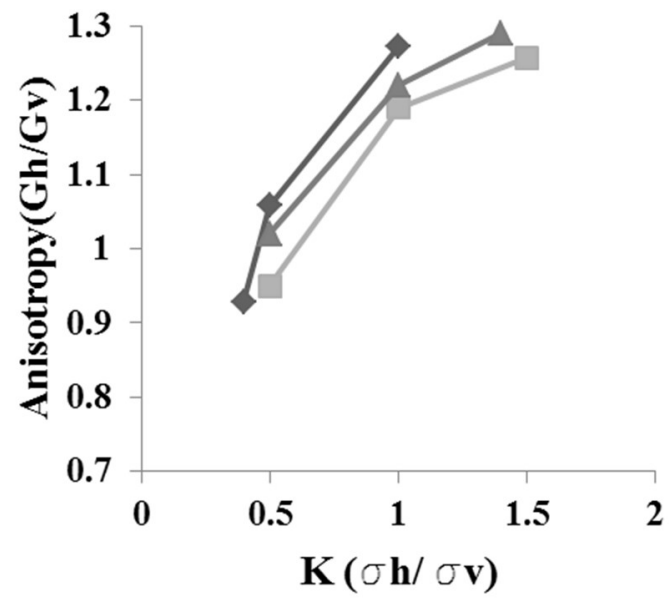

-Anisotropy

-Anisotropy-Tiscino sand (Belloti et al 1996)

-Anisotropy- Toyura sand (Kuwano et al. 1999)

Fig. 6 Anisotropy as function of K 
As shown in Fig. 7, the results between chambers are very similar and the scale effect seems to be reduced. The tendency for higher shear modulus values in small specimens as reported by Omar \& Sadrekarimi (2015) was not found. The results obtained in other stress conditions (in terms of comparing triaxial chambers) were similar. The use of accelerometers brings robustness to the comparison as it validates the obtained results.

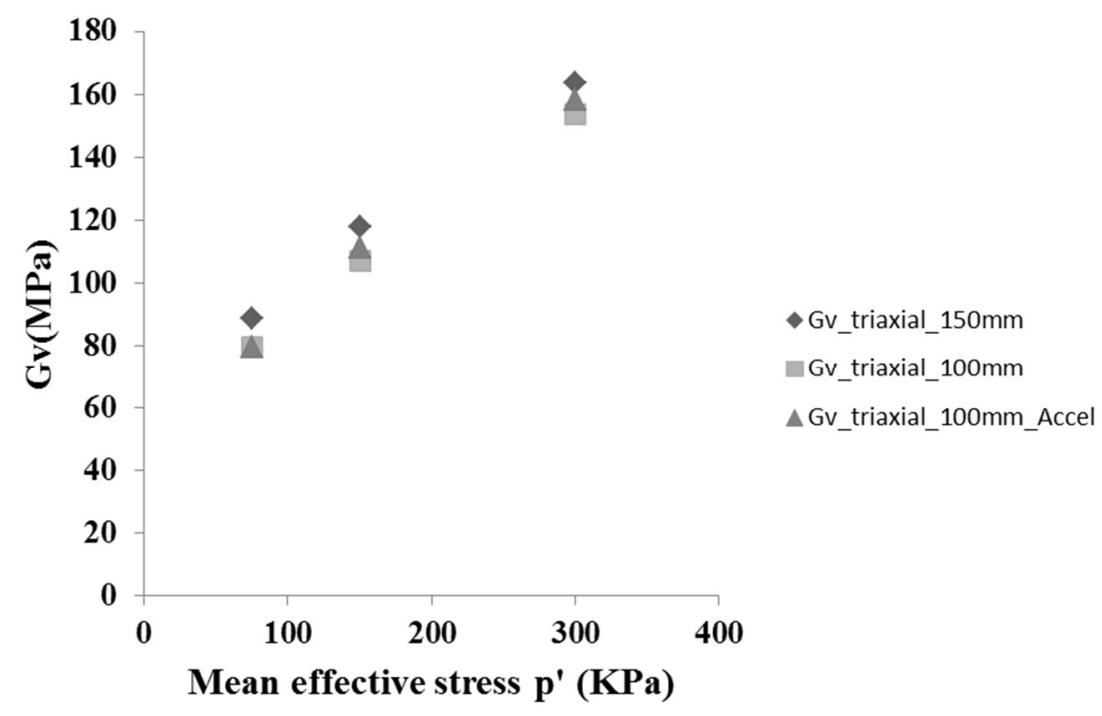

\section{Fig. 7 Vertical shear modulus in different triaxial chambers considering an anisotropic state with a $K$ of 0.4}

Figure 10 shows the results of the material anisotropy under different stress histories. As expected the anisotropy of the sand is lower for lower values of $\mathrm{K}$, emphasizing the importance of the sh/sv relationship on the anisotropy. That can also be inferred from the results of the induced anisotropy, meaning there is less recovering of the anisotropy for a lower K. Regarding the trends of the induced anisotropy assessed under different conditions, they seem to have different evolutions (anisotropy increases for $\mathrm{K}=0.5$, and decreases for $\mathrm{K}=0.4$ ). This may be explained by the fact that when the induced test using $\mathrm{K}=0.5$ was performed, the sand had already experienced much higher stress levels. In contrast, the $\mathrm{K}=0.4$ experiment was made in reloading and unloading stages as can be seen in Fig. 2 . Thus the path of stress level appears to influence the induced anisotropic results. 


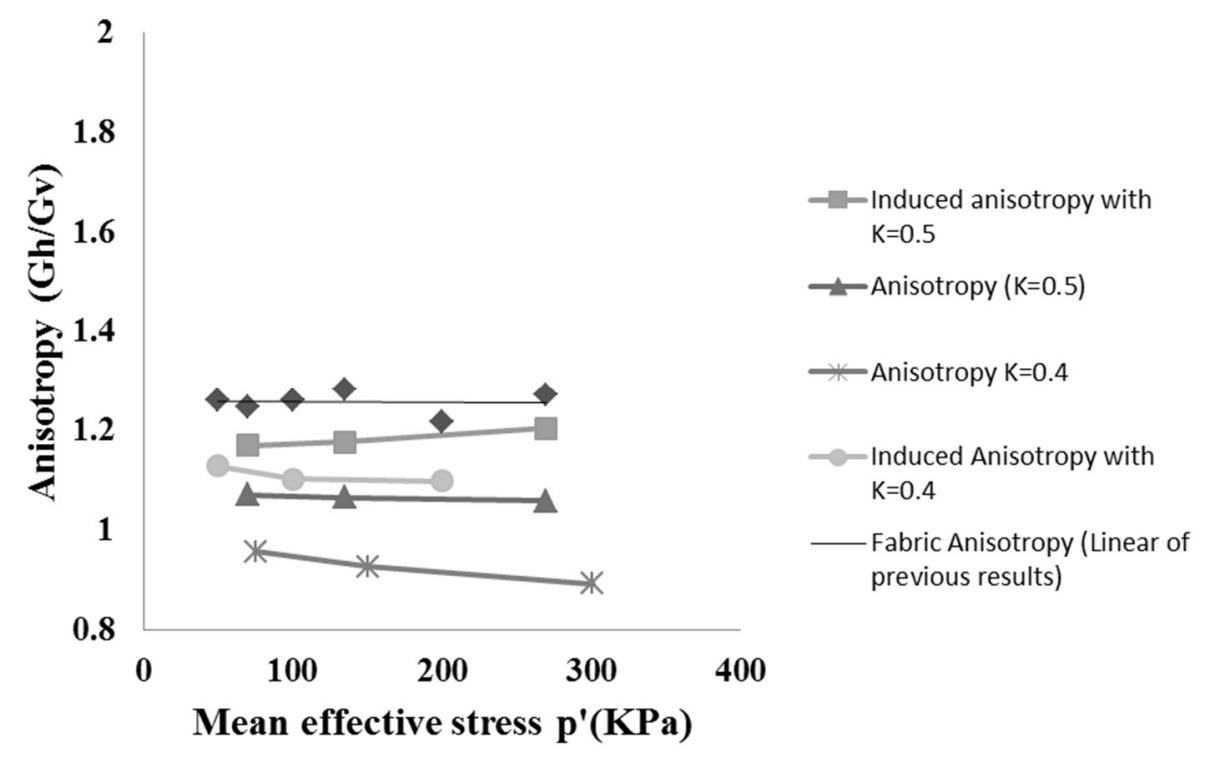

Fig. 8 Effect of the anisotropy stress on the anisotropy of the material

\section{CONCLUSION}

In this paper the anisotropy of a monogranular sand compacted by the pluviation method in terms of shear modulus was assessed for different stress conditions. The anisotropy of the material was found to be dependent of the fabric of the material (inherent anisotropy), the applied effective stress ratio (induced anisotropy) during testing and the stress paths history. The results obtained corroborate other previous research works, showing the predominance of the horizontal modulus over the vertical modulus, which reflects the compaction method, as well as the fabric of the sand. The anisotropic stresses caused an increase of the vertical modulus of the sand over the horizontal modulus. After the anisotropic loading, some recovery of inherent anisotropy can be observed under isotropic stresses. This study also concluded that the scale effects of the tested specimens are not relevant.

\section{ACKNOWLEDGMENTS}

Financial support provided by FCT (Portuguese Foundation for Science and Technology) in the form of the research project WaveSoil (PTDC/ECM/122751/2010).

\section{REFERENCES}

Amat, A.S., 2007. Elastic stiffness moduli of Hostun sand. University of Bristol. Belloti, R., Jamiolkowski, M., Lo Presti, D.C.F. \& O' Neill, D.A., 1996. Anisotropy of small strain stiffness in Ticino sand. Géotechnique, 46(1), pp.115-131. 
Ferreira, C., Martins, J.P. \& Gomes Correia, A., 2013. Determination of the smallstrain stiffness of hard soils by means of bender elements and accelerometers. Geotechnical and Geological Engineering, 6, pp.1-7.

Fioravante, V., 2000. Anisotropy of small strain stiffness of Ticino and Kenya sand from seismic wave propagation measured in triaxial testing. Soils and Foundations, 40(4), pp.129-142.

Gomes Correia, A., Dan Anh, L.D., Koseki, J. \& Tatsuoka, F., 2001. Small strain stiffness under different isotropic and anisotropic stress conditions of two granular granite materials. In Advanced Laboratory Stress-Strain Testing of Geomaterials. pp. 209-215.

Kuwano, R., Connolly, T.M. \& Kuwano, J., 1999. Shear stiffness anisotropy measured by multi-directional bender element transducers. Pre-failure Deformation Characteristics of Geomaterials, 1.

Leung, E.H.Y. \& Ng, C.W.W., 2004. Inherent anisotropic stiffness of decomposed tuff and alluvium. Advances in Geotechnical Engineering: The Skempton Conference, 1.

MARTINS, J. \& Gomes Correia, A., 2015. Comparison between laboratory and field stiffness by wave measurements. Journal of Testing and Evaluation, 43(2), pp.1-13.

Martins, J.P., 2011. Compaction and its influence on the structural behaviour of high speed railways. University of Minho.

Omar, T. \& Sadrekarimi, A., 2015. Effect of triaxial specimen size on engineering design and analysis. International Journal of Geo-Engineering.

Rampelo, S. \& Viggiani, G.M.B., 2001. Pre-failure deformation characteristics of geomaterials. Pre-failure Deformation Characteristics of Geomaterials, 2. 